\title{
Grupos educativos sobre aleitamento: saberes de gestantes
}

\author{
Educational groups on breastfeeding: knowledge of pregnant women \\ Grupos educativos sobre lactancia: conocimiento de la mujer embarazada
}

Recebido: 23/02/2021 | Revisado: 02/03/2021 | Aceito: 03/03/2021 | Publicado: 11/03/2021

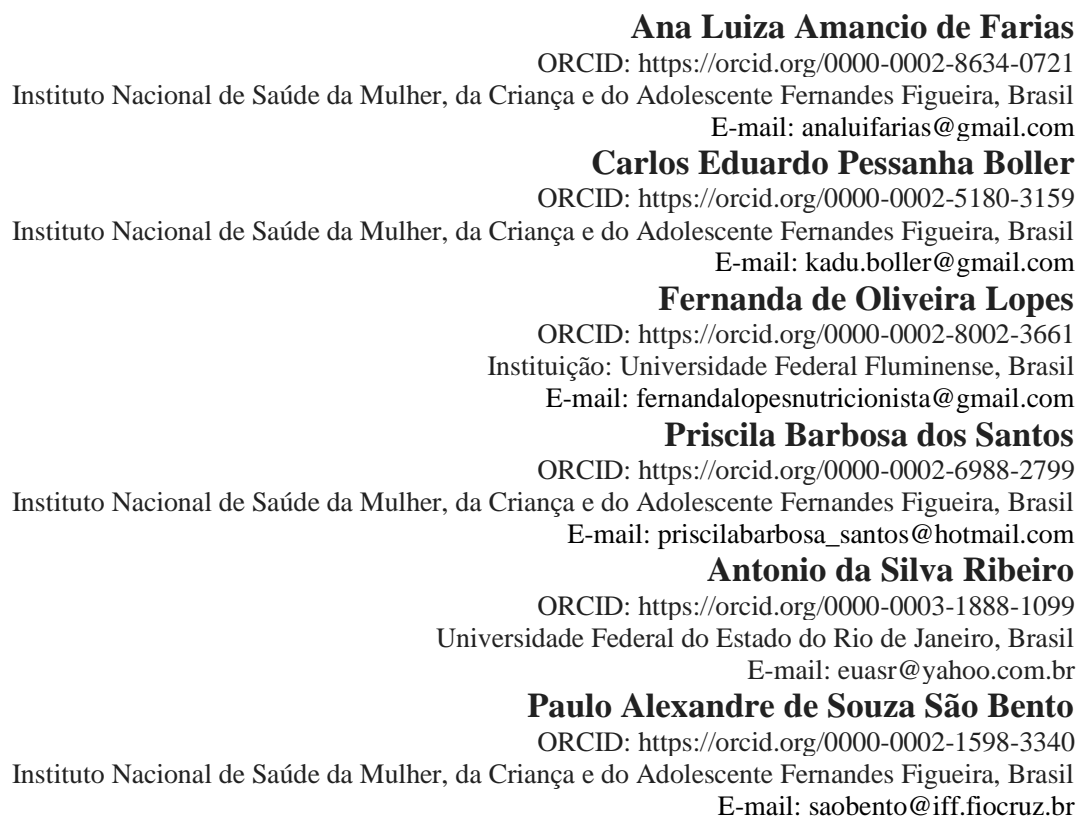

\section{Resumo}

Esta pesquisa objetivou identificar saberes prévios e avaliar os conhecimentos construídos considerando a participação em grupos educativos sobre aleitamento materno, assim como, analisar as interações, entre profissionais e gestantes, que propiciam a construção deste conhecimento a partir dos grupos. A pesquisa de avaliação diagnóstica, processual e somativa foi o método proposto e realizada com 90 gestantes participantes de um grupo educativo em um Banco de Leite Humano, no Rio de Janeiro. Os resultados analisados mostram que as gestantes construíram conhecimentos sobre o assunto (51,1\%), algumas mantiveram saberes que já possuíam $(36,6 \%)$ e na menor parte $(12,2 \%)$ houve desconstrução de saberes. A complexidade do tema e as lacunas presentes na realização dos grupos orientaram a discussão. Como considerações finais propõe-se um deslocamento da educação bancária para a construtivista, priorizando uma pauta simplificada contendo informações elementares, permitindo que estes assuntos sejam tratados na medida em que são demandados.

Palavras-chave: Enfermagem; Aleitamento materno; Saúde da mulher; Educação em saúde.

\begin{abstract}
This research aimed to identify previous knowledge and evaluate the knowledge built considering the participation in educational groups on breastfeeding, as well as to analyze the interactions, between professionals and pregnant women, that allow the construction of this knowledge from the groups. The method proposed was diagnostic, procedural and summative evaluation research and implemented with 90 pregnant women participating in an educational group at a Human Milk Bank, in Rio de Janeiro. The results analyzed shows that pregnant women built knowledge (51.1\%), some maintained knowledge they already had (36.6\%) and some women $(12.2 \%)$ deconstructed the knowledge. The complexity of the theme and the gaps present guided the discussion. As final considerations, the authors propose the strategy of moving from banking to constructivist education, prioritizing a simplified and elementary information, allowing the treatment of these issues, as they are demand.
\end{abstract}

Keywords: Nurse; Breast feeding; Women`s health; Health education.

\section{Resumen}

Esta investigación tuvo como objetivo identificar conocimientos previos y evaluar el conocimiento construido considerando la participación en grupos educativos sobre lactancia materna, así como analizar las interacciones, entre profesionales y gestantes, que permitan la construcción de este conocimiento desde los grupos. La investigación diagnóstica, procedimental y de evaluación sumativa fue el método propuesto y fue realizado con 90 gestantes 
participantes de un grupo educativo en un Banco de Leche Humana, en Río de Janeiro. Los resultados analizados muestran que las gestantes construyeron conocimientos sobre el tema $(51,1 \%)$, algunas mantuvieron conocimientos que ya tenían $(36,6 \%)$ y en la menor parte $(12,2 \%)$ hubo deconstrucción de conocimientos. La complejidad del tema y las brechas presentes en la realización de los grupos guiaron la discusión. Como consideraciones finales, se propone un cambio de la educación bancaria al constructivismo, priorizando una agenda simplificada que contenga información elemental, adhiriéndose a estos temas ya que son requeridos.

Palabras clave: Enfermería; Lactancia materna; Salud de la mujer; Educación en salud.

\section{Introdução}

A gestação é, usualmente, um processo marcado por enormes mudanças. Neste sentido, é muito importante que os espaços de atenção à saúde possam oportunizar trocas entre as gestantes e os profissionais de saúde, tentando identificar saberes e crenças a fim de esclarecer dúvidas e manejar situações de risco. (Brasil, 2012a)

A educação em saúde é primordial em todas as dimensões do cuidar. O profissional de saúde, na proximidade com a clientela, é um agente potente na divulgação de informações, contribuindo para a formação e o desenvolvimento de visão crítica auxiliando pessoas a tomar decisões em situações diversas (Brasil, 2012a). Outra característica é a inclinação em compreender o contexto das mulheres e negociar, sob a luz da ciência, aspectos relacionados ao autocuidado, contribuindo para seu preparo diante de quaisquer situações que possa vivenciar. (Silva et al., 2013)

O Ministério da Saúde (MS) traz ações educativas em grupos como um facilitador para a vivência gestacional. Estabelecer grupos educativos (GE) sobre aleitamento no período pré-natal e puerperal é um cuidado em saúde que, quando presente como estratégia, propicia a troca entre os envolvidos consolidando informações importantes que envolvam não só a gestação, mas também a saúde da criança, da mulher e da família (Brasil, 2012a; Seima, Michel, Méier, Wall, \& Lenardt, 2011; Barbosa, Santos, Moraes, Rizzardi, \& Corrêa, 2018). Contudo, para isso, a abordagem do profissional deve ser horizontalizada, pois assim, terá maior possibilidade de promover confiança e obter maior adesão, tanto na participação como na interação nesses GE. (Progianti \& Costa, 2008)

Os GE sobre amamentação podem priorizar vivências anteriores, experiências provenientes de outras pessoas, informações sobre o assunto etc. Todos os temas correlatos ao processo de oferta do leite humano ao bebê devem ser discutidos, abordando, inclusive, a possibilidade de internação da gestante durante alguns dias devido ao parto, pois este não deve ser entendido como um impedimento para o aleitamento. (Brasil, 2012a)

Considerando os possíveis espaços de realização dos GE, refletir sobre a forma com que as práticas educativas podem ocorrer no interior dos Bancos de Leite Humano (BLH) levantam algumas questões norteadoras: as gestantes trazem saberes prévios sobre aleitamento quando frequentam GE?; é possível identificar os saberes prévios das gestantes sobre o aleitamento e avaliar se existe alguma modificação após participação em grupos educativos?; as mulheres e profissionais possuem uma atitude de negociação do cuidado sobre amamentação, que privilegie a troca, nos grupos educativos?

Assim, este artigo objetiva: identificar os saberes prévios das gestantes antes da sua participação em grupo educativo sobre aleitamento; avaliar os conhecimentos construídos pelas gestantes após a participação em um grupo educativo sobre aleitamento; analisar se as interações entre profissionais/mulheres, e outras situações correlatas, propiciam a construção do conhecimento através do grupo educativo sobre aleitamento.

Este estudo almeja colaborar como construto teórico a ser dialogado com outras pesquisas sobre o tema. Propiciar, quiçá, reunir um arcabouço capaz de valorizar a importância de GE e estratégias em prol de uma saúde pública pautada em princípios humanísticos de assistência. 


\section{Metodologia}

Esta pesquisa possui natureza quali-quantitativa e apoiou-se em Pereira, Shitsuka, Parreira e Shitsuka (2018) a partir do entendimento de que não são naturezas de investigação excludentes. Ao contrário, há complementaridade e possibilidades para uma compreensão ampliada do fenômeno estudado. O eixo qualitativo buscou uma descrição e interpretação detalhada, enquanto o eixo quantitativo possibilitou a matematização e a metrologia dos dados que foram analisados estatisticamente.

Foi desenhado a partir de avaliações diagnóstica, processual e somativa realizado no GE com o tema de aleitamento às gestantes de um Instituto Nacional de referência à mulher no Rio de Janeiro - RJ. Os GE ocorriam semanalmente e possuíam, em média, 12 participantes. A coleta dos dados se deu de julho a agosto de 2018. A seleção da amostra se deu por conveniência, a partir do convite verbal a todas as gestantes que participaram dos grupos no período citado.

Como critério de inclusão utilizou-se: ser gestante e como critério de exclusão: idade inferior a 18 anos e não realizar, independente do motivo, as duas avaliações (pré e pós-teste). A pesquisadora principal participou do GE, anteriormente ao período de coleta, buscando se instrumentalizar no sentido de elaborar o Instrumento de Coleta de Dados, segundo os conteúdos apresentados. Foram incluídas 100 gestantes para a análise em 14 encontros, porém 10 correspondiam aos critérios de exclusão. Assim, o número de participantes desta pesquisa foi de 90.

A coleta dos dados ocorreu em três momentos distintos, antes da realização do GE (avaliação diagnóstica, através do pré-teste), após o encerramento do GE (avaliação somativa, através do pós-teste) e durante a realização dos grupos (análise processual), através da observação ativa no interior dos grupos e posterior anotação em caderno de campo com as impressões referente aos 14 encontros.

A análise referente às coletas diagnóstica e somativa foram feitas sob abordagem quantitativa. Sendo utilizada a análise de estatística simples através do programa Excel do pacote Office 2013. A análise qualitativa foi realizada a partir do caderno de campo, transferindo assim o foco para o processo e não para o produto, como conduzido na análise anterior.

Quanto às questões éticas, o estudo obedeceu aos preceitos e as normas editadas pela Resolução 466/12 do Conselho Nacional de Saúde (CNS) (Brasil, 2012b) sendo aprovado pelo Comitê de Ética em Pesquisa sob parecer nº 2.757.746, CAAE n91387918.0.0000.5269 e as participantes assinaram um Termo de Consentimento Livre e Esclarecido (TCLE).

As informações foram arquivadas de posse dos pesquisadores e a identidade das participantes foi substituída por números de forma a inviabilizar a identificação posterior, garantindo assim o anonimato.

\section{Resultados}

No que tange as coletas diagnóstica e somativa, observou-se que, em uma leitura geral, 51,1\% das gestantes tiveram uma construção de conhecimento (dentro do que se considerou aquisição do conhecimento científico - mais acertos no pósteste do que no pré-teste), 12,2\% desconstruíram o saber prévio quando em contraste com as normativas científicas (mais acertos no pré-teste do que no pós) e 36,6\% mantiveram o saber trazido (mantendo a mesma quantidade de acertos em ambos os momentos). Porém, a partir da premissa que cada questão corresponde a um conhecimento ofertado durante o GE (Quadro 1), infere-se que existam dificuldades relacionadas à $40 \%$ do conteúdo ofertado, sendo necessário uma análise individualizada para cada área do saber. 
Quadro 1: Temas analisados e seus conhecimentos.

\begin{tabular}{|c|c|c|c|}
\hline Tema analisado & Possuem & $\begin{array}{l}\text { Pré-teste } \\
\text { (saberes) }\end{array}$ & $\begin{array}{c}\text { Pós-teste } \\
\text { (conhecimento) }\end{array}$ \\
\hline \multirow{2}{*}{ Aleitamento exclusivo } & Sim & 85,56 & 95,56 \\
\hline & Não & 14,44 & 4,44 \\
\hline \multirow{2}{*}{ Golden hour } & Sim & 82.22 & 95,56 \\
\hline & Não & 17.78 & 4.44 \\
\hline \multirow{2}{*}{ Produção de leite } & Sim & 80,00 & 88,89 \\
\hline & Não & 20,00 & 11,11 \\
\hline \multirow{2}{*}{ Prevenção de fissura mamilar } & Sim & 82,22 & 95,56 \\
\hline & Não & 17,78 & 4,44 \\
\hline \multirow{2}{*}{ Condutas quanto a mama cheia } & Sim & 82.22 & 96,67 \\
\hline & Não & 17,78 & 3,33 \\
\hline \multirow{2}{*}{ Sinais do lactente durante a mamada } & Sim & 58,89 & 78.89 \\
\hline & Não & 41,11 & 21,11 \\
\hline \multirow{2}{*}{ Hábito de vida da lactante } & Sim & 94,44 & 94,44 \\
\hline & Não & 5,56 & 5,56 \\
\hline \multirow{2}{*}{ Preparo das mamas durante a gestação } & Sim & 62,22 & 57,78 \\
\hline & Não & 37,78 & 42,22 \\
\hline \multirow{2}{*}{ Cuidados pré-amamentação } & Sim & 13,33 & 7,78 \\
\hline & Não & 86,67 & 92,22 \\
\hline \multirow{2}{*}{$\begin{array}{l}\text { Posição do lactente durante a } \\
\text { amamentação }\end{array}$} & Sim & 77,78 & 68,89 \\
\hline & Não & 22,22 & 31,11 \\
\hline
\end{tabular}

Fonte: Autoria própria (2020).

O Quadro 1 especifica, na primeira coluna, os temas que foram analisados nesta pesquisa e demonstra, nas colunas ao lado, como as gestantes chegam ao GE com determinado saber, assim como, o conhecimento que constroem após a realização da atividade do GE. Desta forma, é possível identificar as construções, desconstruções e manutenções dos saberes/conhecimentos.

As questões foram divididas em três vertentes: temas que contribuíram para a construção do conhecimento das gestantes (a saber, aleitamento exclusivo, golden hour, produção de leite, prevenção de fissura mamilar, condutas quanto a mama cheia e sinais do lactente durante a mamada); temas que não alteraram a relação saber versus conhecimento (hábitos de vida da lactante) e temas que contribuíram para a desconstrução dos saberes prévios das gestantes (preparo das mamas durante a gestação, posição do lactente durante a amamentação e cuidados com as mamas antes de amamentar).

No que toca a primeira vertente, em uma leitura inicial, pode-se observar nas questões que houve construção do conhecimento a moda de erro no pós-teste foi de 4,44\% e a média de incremento do conhecimento foi de 13,3\%. Destaca-se a questão sobre os sinais do lactente durante a mamada, que apesar de apresentar uma melhora no panorama do conhecimento, demonstrou que $21,11 \%$ das mulheres permaneceram com um saber equivocado quando em comparação ao conhecimento científico, destoando dos demais assuntos.

A avaliação sobre os hábitos de vida da lactante (segunda vertente), apesar de não ter alterado a relação, apresentou a maior frequência entre os saberes $(94,44 \%)$ e foi a quinta maior frequência entre os conhecimentos. No que se relaciona a terceira vertente, a média de erro aumentou em 7,78\% e os temas (preparo das mamas durante a gestação, cuidados préamamentação e posição do lactente durante a amamentação) possuem particularidades em seus resultados.

O primeiro tema possui uma quantidade de acertos no pré e no pós-teste superior a 50\%, apesar disso, observa-se uma convergência entre a frequência de saberes e conhecimentos, o que caracterizaria uma fragilidade na abordagem desse tema durante a realização do grupo. No que se refere a segunda destaca-se que a ausência deste saber (pré-teste) é 6,5 vezes maior do que seu acerto. Além disso, após a orientação dialogada em GE, a taxa de desconhecimento (erro no pós-teste) supera em quase 12 vezes os acertos, aproximando-se de um total desconhecimento (100\%). Quanto ao terceiro tema, apesar de ter 
ocorrido redução do conhecimento, o mesmo ainda se apresenta de forma relevante, permanecendo presente em aproximadamente 7 em cada 10 gestantes.

Quanto à análise processual, uma quarta vertente foi elaborada com base em algumas inferências observacionais e necessárias, na busca de compreender esse difícil trânsito entre a construção e desconstrução de saberes/conhecimentos. Pois ao contrário das hipóteses da pesquisa, deparou-se com a desconstrução de saberes/conhecimentos em pós-teste de GE em BLH e levantou indagações sobre que contextos favoreceriam esse desfecho inesperado.

A participação de gestantes oriunda de captação oportunística leva ao questionamento sobre a voluntariedade de participação nestes GE, pois eles funcionam como um espaço de controle. É possível controlar e se certificar para que não haja interferências durante a realização do exame, por exemplo com a ingesta de água e/ou outros líquidos, porquanto na ocorrência disso, ou na vigência de episódios de êmese, o exame precisa ser refeito.

\section{Discussão}

Discutiu-se, frente aos temas analisados e a avaliação processual, a partir de três categorias: 'A construção do conhecimento: pelas balizas objetivas da ciência'; 'A manutenção e desconstrução do saber: a ênfase do arcabouço cultural prévio' e 'Ruídos da negociação: os membros de trânsito entre saber e conhecimento'.

\section{A construção do conhecimento: pelas balizas objetivas da ciência}

O MS e a Organização Mundial da Saúde (OMS) definem que o aleitamento exclusivo é a oferta de leite humano até os seis meses, proveniente diretamente da mama da mulher, ordenhado ou leite humano pasteurizado, sem quaisquer outros tipos de líquidos ou sólidos, com exceção de medicamentos, vitaminas, sais de reidratação oral. Cumpre ressaltar, que a amamentação cruzada não pode ser fonte de oferta direta. (Brasil 2015a; Brasil, 2015b; Dias et al., 2019)

O leite humano é um alimento completo e de grande importância, pois fornece todos os nutrientes, vitaminas e minerais nas quantidades necessárias para o melhor desenvolvimento e crescimento do bebê, não só no período neonatal, mas com benefícios futuros para a criança (Brasil, 2015a; Brasil, 2015b; Dias et al., 2019). Para o bebê, os benefícios do aleitamento exclusivo são: os imunológicos; os relacionados ao vínculo mãe e bebê e a menor probabilidade de desenvolvimento de doenças crônicas. E para a mulher: previne o câncer de mama e ovários; auxilia na perda de peso e previne a hemorragia pós-parto (causa de 25\% das mortes maternas). (Brasil, 2013a; Brasil 2015a; Brasil, 2015b; Dias et al., 2019)

A respeito da 'Golden hour' (também conhecida como hora de ouro) é sabido que o quarto passo da IHAC (Iniciativa Hospital Amigo da Criança) preconiza o aleitamento na primeira hora de vida. O início precoce tem inúmeros benefícios, principalmente, por prevenir doenças crônicas, além da redução da morbimortalidade neonatal. (Brasil, 2015b)

Caso $90 \%$ das crianças fossem amamentadas exclusivamente até os seis meses (como recomendado pela OMS desde 2002), e concomitante a introdução alimentar, evitar-se-ia 13\% de mortes em menores de cinco anos (Silva, 2013). Porém, esse panorama não é satisfatório. Em 2008, por exemplo, havia uma prevalência do aleitamento exclusivo de $41 \%$, sendo a duração média de 2 meses. (Esteves, Daumas, Oliveira, Andrade, \& Leite, 2014; Brasil, 2013a; Dias et al., 2019)

O questionamento sobre a 'Produção de leite' foi introduzido, nesta pesquisa, na perspectiva de abordar os mitos que envolvem e perpassam o período gravídico-puerperal. As alternativas de respostas eram comer canjica, beber água, tomar cerveja preta ou leite de vaca. É sabido que, culturalmente, há uma valorização destes produtos atrelada a um possível aumento da produção de leite. Entretanto, as evidências científicas não apontam para estes benefícios. Além disso, o uso da cerveja preta acarreta malefícios relacionados ao uso do álcool e da cafeína (Brasil, 2010). Dos líquidos elencados, somente a água tem indicação baseada em estudos. (Ichisato \& Shimo, 2001; Lima, Silva, Tsupal, Melhem, Brecailo \& Santos, 2016) 
Sobre as 'fissuras mamilares' sabe-se que a pega e o posicionamento incorreto são as principais causas deste fenômeno (Febrasgo, 2018). Como estratégias de prevenção têm-se o posicionamento correto do bebê, assim como, da pega. Na vigência desse tipo de intercorrência recomenda-se tratar a fissura mamilar com o próprio leite humano do fim da mamada, usado de forma tópica nos mamilos e aréolas. (Brasil,2012a)

Algumas observações quanto ao tratamento de fissuras mamilares são importantes quando se avalia as recomendações existentes. (Brasil, 2015a; Brasil, 2015b) A Federação Brasileira das Associações de Ginecologia e Obstetrícia (Febrasgo, 2018) ao mesmo tempo em que propõe o tratamento úmido, contraindicado exposição ao sol, menciona o uso de terapia com laser, citando estudos que alegam benefícios como diminuição da dor e do desmame precoce. O uso de lanolina purificada é acionado pelo MS (Brasil, 2015a; Brasil, 2015b) e pela Federação Brasileira das Associações de Ginecologia e Obstetrícia (Febrasgo, 2018) como auxiliares, desde que afastada infecção nos mamilos. Todavia, não há evidências que a lanolina seja capaz de acelerar o processo cicatricial. (Brasil, 2015a; Brasil, 2015b)

Na discussão sobre 'mamas cheias' alerta-se para os prejuízos relacionados a manutenção da amamentação, pois as aréolas ficam tensionadas ocasionando prejuízos na abocanhadura. Este fenômeno ocorre em virtude de excessiva produção de leite ou por sucção prejudicada do bebê levando a baixa e/ou inadequada ingesta. A massagem e a ordenha preveem futuras complicações como ingurgitamento, bloqueio de ductos lactíferos, mastite e, até mesmo, abcesso mamário. (Brasil 2015a; Brasil, 2015b; Dias et al., 2019)

Tomando-se como assunto os 'sinais da amamentação efetiva', cabe pontuar, nessa questão em especial, a elevada taxa $(21,11 \%)$ de erro no pós-teste. Apesar de ter ocorrido construção de conhecimento, existiam três possíveis opções erradas, e nenhuma delas foi completamente desmistificada durante o GE.

Recomenda-se que a amamentação seja em livre demanda, sem restrições de horários e de duração da mamada. Para o bebê mamar bem e ganhar peso é necessário que ele esvazie a mama, recebendo assim o leite posterior, mais calórico. Com isso, promove-se à saciedade e ganho de peso. Não se pode estipular um tempo para o esvaziamento da mama, isso varia na relação entre o binômio mulher-bebê e pelo intervalo entre as mamadas. (Brasil 2015a; Brasil, 2015b e, Dias et al., 2019)

\section{A manutenção e desconstrução do saber: a ênfase do arcabouço cultural prévio}

Os temas contemplados nesta categoria trazem à tona questionamentos associados aos objetivos do GE, pois um deles reside na intenção de que os saberes prévios das mulheres possam ser discutidos e voltados para a construção de um conhecimento com base científica. Considerou-se como enunciado de categoria a manutenção/desconstrução de saber, pois estas mulheres ou mantiveram seus saberes prévios ou não conseguiram transitar dos seus saberes para o conhecimento científico. Isto é, na maioria dos temas, no que toca a desconstrução, elas chegaram com saberes prévios sobre aleitamento em consonância com o conhecimento científico e, por algum motivo, desconstruíram-no assinalando respostas incorretas no pósteste.

O tema 'Hábitos de vida da lactante' foi o único em que houve manutenção do saber e traz a ideia de que a mulher pode manter, como hábito, durante a amamentação a realização de exercícios físicos que são recomendados desde a gestação. A atividade física, principalmente aeróbica, proporciona benefícios, contribuindo com uma melhor adaptação as modificações fisiológicas do organismo durante a gestação, além de proporcionar vivências positivas no pós-parto. (Brasil, 2012a)

Os temas nos quais as mulheres cursaram com desconstrução no saber evocam preocupações sobre a propensão delas apresentarem dificuldades ou intercorrências no processo de amamentação, considerando que podem afetar, em potencial, a vida cotidiana das lactantes a partir de dúvidas, incertezas ou, até mesmo, conhecimentos equivocados. E, diante disso, caso as mulheres não procurem ajuda especializada, há potencial para danos em sua saúde e na do bebê. Cabe destacar que a desconstrução acarreta o aumento de crenças equivocadas e essas podem ser objeto de discussões futuras. 
Quando feito o questionamento sobre o tema 'preparo das mamas durante a gestação', a OMS (Brasil, 2012a) preconiza ofertar à gestantes a possibilidade de participação em GE, pois é o local onde podem compartilhar experiências com os profissionais de saúde sobre os benefícios do aleitamento, conversar sobre pega, posicionamento e técnicas que sejam facilitadoras da amamentação. Nestes espaços também é possível trabalhar as crenças, mitos e/ou experiências prévias dessas mulheres, além de esclarecer que se deve evitar o uso de sabonetes, pomadas e óleos no mamilo. Durante os GE desmistificouse sobre muitos aspectos relacionados ao aleitamento, fortalecendo a ideia de que durante a gestação não é necessário fazer nada nas mamas. Deixaram a estratégia do banho de sol nos mamilos como livre escolha da gestante, com vistas a um possível fortalecimento da região aréolo-mamilar.

A respeito dos 'cuidados com as mamas antes de amamentar', a Agência Nacional de Vigilância Sanitária recomenda como de fundamental importância a higienização das mãos, pois elimina a flora transitória e diminui a flora residente. (Brasil, 2013b) Deve ser realizada antes do ato de amamentar, evitando assim o transporte para as mamas de microrganismos causadores de doenças (Brasil, 2013a). Este tema não foi enfatizado nos GE, pois a preocupação gira em torno de pega e posição; e do aleitamento exclusivo e em livre demanda. Este aspecto preocupou os autores deste paper, tendo em vista a resposta que teve a maior frequência de escolha, que foi a ação de lavar as mamas. Este ato pode levar ao aparecimento de fissuras por ressecamento da pele.

No que corresponde a 'posição do lactente durante a amamentação', a desconstrução do saber acarreta desdobramentos no processo de amamentação e preocupações para a equipe de profissionais da área. Porém, tal cenário é amenizado ao se observar que mesmo tendo uma redução na taxa de acertos, este tema apresenta uma frequência superior ao dobro do erro o que caracteriza, ainda, um conhecimento significativo. Alguns pontos-chave a respeito do posicionamento são amplamente divulgados e devem ser observados, como o corpo do bebê encostado ao corpo (preferencialmente abdome do bebê pareado ao abdome da mulher) e a adoção de posicionamento confortável por parte da mulher (Brasil 2015a; Brasil, 2015b). A Febrasgo (2018) corrobora e recomenda que o momento deve ser prazeroso, pois o não ajuste traz transtornos que ocasionalmente pode estimular um desmame precoce.

\section{Ruídos da negociação: os meandros do trânsito entre saber e conhecimento}

A última análise, a processual, subsidia a utilização de elementos operacionais para a compreensão sobre o saber desconstruído/mantido por gestantes após a participação em GE sobre aleitamento. Para as mulheres que não construíram o conhecimento, o trabalho apontou para dois movimentos relacionados aos seus saberes, a desconstrução (36,6\%) e a manutenção (12,2\%). Foi fundamental discutir este aspecto, avalizado pela observação participante e pelo material que compôs o caderno de campo da pesquisadora, no concernente aos cenários e práticas onde ocorrem os GE.

As gestantes participam dos GE por captação oportunística, isto é, uma vez que estão no BLH para a realização de um exame (TOTG) cabe, durante o tempo de espera, participar de um GE. Elas, em jejum, saem de suas residências para vir a uma instituição de saúde. Durante a realização do exame precisam ingerir $75 \mathrm{~g}$ de glicose, que tem potencial para levar ao enjoo e, consequente, êmese. Assim, cumpre reconhecer estes elementos como dificultadores de qualquer processo educacional proposto - ansiedade, medo, estresse, pirose, êmese, falta de desejo em participar e o fato de estarem dentro de um hospital.

Observou-se que não há uma uniformização das metodologias utilizadas pelos diferentes profissionais que conduzem os grupos. Na maioria das vezes a metodologia utilizada é tradicional, na qual o profissional transmite o conhecimento. A proposta da uniformização das metodologias pode ser uma estratégia de sistematização metodológica, feita a partir de uma pauta mínima de conhecimentos a serem discutidos, treinamento da equipe, além da realização de exercícios com metodologias ativas de aprendizagem. 
A formação acadêmica em saúde é balizada por construtos teóricos baseados em modelos tradicionais ou também chamados de bancários (Lopes, Dalmolin, Durand, Rumor, Heidemann \& Koch, 2017). Educadores em saúde podem ficar acomodados em não modificar seus modelos pautados na transmissão de informações. Essa crítica busca evocar a importância de sensibilizar profissionais de saúde para que exerçam uma reflexão sobre os modelos de ensino, nos grupos, e que potência eles podem representar.

No que cabe a esta pesquisa, a pergunta: 'as mulheres e profissionais possuem uma atitude de negociação do cuidado sobre amamentação, que privilegie a troca, nos GE?’ tem resposta negativa. No início da realização dos grupos há um movimento de participação, quando todas as gestantes são convidadas a se apresentar. A partir disso, é que a educadora começa a tecer suas falas sobre o tema, em alguns casos começando pelas dúvidas. Até aqui, a lógica é construtivista, contudo, ela perde força na medida em que o grupo se amolda a uma pequena palestra onde busca-se esgotar, ao máximo, informações sobre o aleitamento.

Para além de um grupo onde os cuidados possam ser negociáveis, sugere-se a metodologia de Paulo Freire, que propõe que a educação, em geral, inclua: a vivência dos sujeitos; problemas e angústias; os contextos; o estímulo a decisão/participação/colaboração; a responsabilidade social e política. Freire recomenda a ação dialogada entre educadores e educandos a fim de estimular uma construção conjunta de conhecimentos, possibilitando a negociação do cuidado, valorizando a história de vida das pessoas. (Linhares, Pontes \& Osório, 2014)

Sugere-se, assim, como estratégia didático-pedagógica, a utilização de uma pauta mínima (Figura 1) para a condução dos grupos, no sentido de nortear caminhos na relação profissionais/mulheres, sistematizando a proposta, mas sem engessá-la. A ideia é que o cuidado possa ser negociado de forma livre tendo a mulher, e o período vivido por esta, como pauta central, sendo aprofundado no desenvolvimento de cada um dos três eixos propostos para abordagem em todos os grupos.

Figura 1: Proposta de pauta mínima.

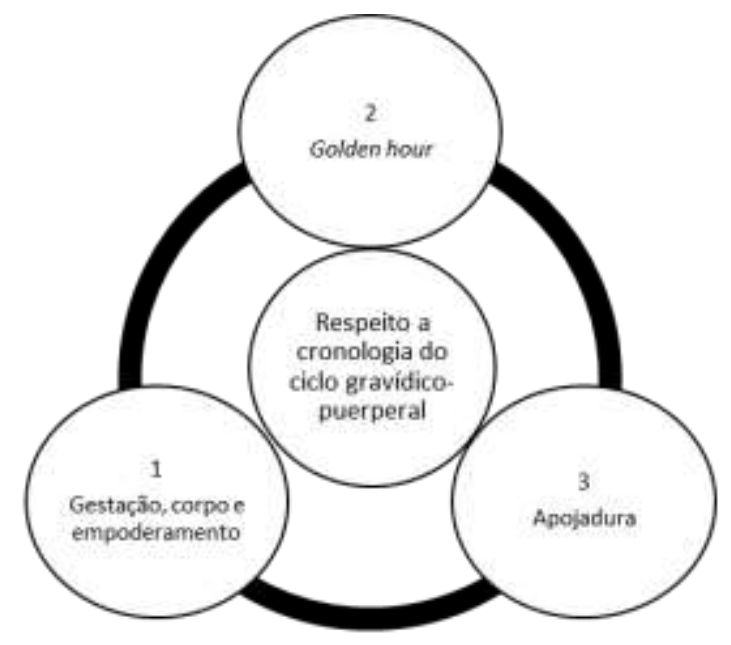

Fonte: Autoria própria (2020).

É importante observar, no diagrama da Figura 1, que os três eixos propostos compõem um único sistema que se intitulou de 'pauta mínima'. É apresentado em círculos, pois o entendimento da proposta deve ser cíclico, mesmo que a ideia seja a abordagem sequencial a partir da numeração atribuída. Isto é, parte-se da ideia de que o primeiro eixo possui conteúdos relacionados a gestação, seguido do segundo relacionado ao momento do parto e, por fim, o terceiro relacionado ao puerpério. A sequência apenas organiza os temas ao redor da cronologia do clico gravídico-puerperal, que podem (e devem) ser abordados em qualquer momento requerido, desde que seja uma necessidade, em respeito ao movimento cíclico do diagrama. 
O primeiro eixo da pauta mínima traz os elementos relacionados a gestação, corpo e empoderamento. É importante trabalhar as informações que cercam a mulher, pois muitas não verbalizam as dúvidas. Falar do seu próprio corpo e de seus órgãos sexuais é, para algumas mulheres, um misto de vergonha e até desconhecimento relacionado às mudanças gestacionais. Desmitificar, por exemplo, que o tipo do mamilo e saída (ou não) de colostro não as torna mais ou menos capazes e autossuficientes para suprir as necessidades de bebê. (Brasil, 2012a)

A abordagem da Golden Hour é sugerida, na pauta mínima, como segundo eixo. Esse conhecimento ganha uma posição de destaque quando se toma como base a existência de unidades de referência para alto risco fetal, onde é necessária uma avaliação da vitalidade do bebê ao nascer e, infelizmente, em alguns casos não será possível amamentar na primeira hora de vida. Porém, é importante enfatizar que, preferencialmente, se não tiver nenhum tipo de intercorrência, é preconizado que se faça. (Brasil, 2012a)

Fechando o ciclo, no terceiro eixo da pauta mínima, traz-se a importância em dar ênfase na Apojadura. A apojadura acontece até o $3^{\circ}$ ou $4^{\circ}$ dia após o parto. (Brasil, 2015a). É o período em que mais podem ocorrer fissuras mamilares, perda da pega, inserção de bicos artificiais e mamadeiras e, até mesmo, o desmame precoce. (Brasil, 2015a) Apesar de desconfortável, é preciso deixar claro a importância desse processo. Falar e apresentar medidas que possam ajudar as mulheres a experienciarem este período positivamente. (Brasil 2015a; Brasil, 2015b; Febrasgo, 2018)

É a partir deste ponto de vista que se valoriza o deslocamento da educação bancária para a lógica construtivista. Doravante, que se reflita sobre os GE realizados com pauta mínima de conhecimentos, considerando de um lado os conhecimentos a serem abordados pelos profissionais e noutro os elementos que possam ser trazidos pelos grupos. No âmbito da negociação é possível melhorar a captação das informações e buscar efetivar o processo de transição de saberes para conhecimentos.

\section{Considerações Finais}

Este estudo discutiu as construções do conhecimento por gestantes em um GE sobre aleitamento a partir da identificação de saberes prévios e a avaliação de conhecimentos construídos. Os achados apontaram para $51 \%$ de construção do conhecimento, mas a desconstrução dos saberes prévios foi significativa. Assim, couberam alguns apontamentos no sentido de compreender elementos que fragilizam a estratégia do trabalho executado e para pensar em alternativas tecendo propostas. Em síntese, a principal, é a utilização de metodologias que possibilitem, de fato, uma construção negociável entre o saber que as mulheres trazem dialogados com profissionais, no espaço relacional e de discussão de GE, baseados em uma pauta mínima de conhecimentos fundamentais.

No concernente a publicações vindouras, sugere-se a realização de novos trabalhos que permitam a discussão, provocada nesta pesquisa, a partir de cenários e contextos diferenciados. A realização de GE, não somente em aleitamento, é uma realidade presente em muitos serviços de saúde. Contudo, cabe o questionamento sobre a avaliação das estratégias metodológicas acionadas e isso é um potente disparador para investigações originais. Além disso, é preciso estudar e aprofundar os elementos capazes de interferir, positivamente e negativamente, na construção de conhecimento proporcionado por GE e suas metodologias utilizadas.

\section{Referências}

Barbosa, L. N., Santos, N. C., Moraes, M. A. M., Rizzardi, S. D., \& Corrêa, E. C. (2018). Prevalência de práticas educativas acerca do aleitamento materno exclusivo (AME) em Cuiabá-MT. Escola Anna Nery, 19(1), 147-153. 10.5935/1414-8145.20150020.

Brasil. (2012a). Cadernos de Atenção Básica n³2. Atenção ao Pré-Natal de Baixo Risco. Brasília - DF: Ministério da Saúde.

Brasil. (2012b). Conselho Nacional de Saúde. Resolução no 466 de 12 de dezembro de 2012. Brasília - DF: Ministério da Saúde. 
Research, Society and Development, v. 10, n. 3, e17810313229, 2021

(CC BY 4.0) | ISSN 2525-3409 | DOI: http://dx.doi.org/10.33448/rsd-v10i3.13229

Brasil. (2013a). Além da sobrevivência: práticas integradas de atenção ao parto, benéficas para a nutrição da saúde de mães e crianças. Brasília - DF: Ministério da Saúde.

Brasil. (2013b). Anexo 1: Protocolo para a prática de higiene das mãos em serviços de saúde. Ministério da Saúde, Anvisa/Fiocruz, Brasília - DF.

Brasil. (2015a). Cadernos de Atençã Básica n²3. Saúde da Criança, Aleitamento Materno e Alimentação Complementar (2a ed.). Brasília - DF: Ministério da Saúde.

Brasil. (2015b). Estratégia nacional para promoção do aleitamento materno e alimentação complementar saudável no Sistema Único de Saúde: manual de implementação. Brasília - DF: Ministério da Saúde.

Brasil. (2010). Amamentação e uso de medicamentos e outras substâncias (2a ed.). Brasília - DF: Ministério da Saúde.

Dias, L. M. O., Batista, A. S., Brandão, I. M., Carvalho, F. L. O., Martins, F. M., Costa, D. M. .... Junior, L. R. G. (2019). Amamentação: influência familiar e a importância das políticas públicas de aleitamento materno. Revista Saúde em Foco, 11, 634-648. https://portal.unisepe.com.br/unifia/wpcontent/uploads/sites/10001/2019/06/057_Amamenta\%C3\%A7\%C3\%A3o-Influ\%C3\%AAncia-familiar-e-a-import\%C3\%A2ncia-das-pol\%C3\%ADticas-

p\%C3\%BAblicas-de-aleitamento-materno_634_a_648.pdf.

Esteves, T. M. B., Daumas, R. P., Oliveira, M. I. C., Andrade, C. A. F., \& Leite, I. C. (2014). Fatores associados à amamentação na primeira hora de vida: revisão sistemática. Revista de Saúde Pública, 48(4), 697-708. 10.1590/S0034-8910.2014048005278.

Febrasgo - Federação Brasileira de Ginecologia e Obstetrícia (2018). Amamentação.(vol. 6).

Ichisato, S. M. T., \& Shimo, A. K. K. (2001). Aleitamento materno e as crenças alimentares. Revista Latino-Americana de Enfermagem [online]. 9(5). 70-6. $10.1590 /$ S0104-11692001000500011.

Lima, M. M. L., Silva, T. K. R., Tsupal, P. A., Melhem, A. R. F., Brecailo, M. K., \& Santos, E. F., (2016). A influência de crenças e tabus alimentares na amamentação. O mundo da saúde, São Paulo; 40(2): 221-229. 10.15343/0104-7809.20164002221229.

Linhares, F. M. P., Pontes, C. M., \& Osório, M. M. (2014). Construtos teóricos de Paulo Freire norteando as estratégias de promoção à amamentação. Revista Brasileira de Saúde Materno Infantil [online], 14(4), 433-439. 10.1590/S1519-38292014000400013.

Lopes, C. R., Dalmolin, I. S., Durand, M. K., Rumor, P. C. F., Heidemann, I. T. S. B., \& Koch, C. (2017). Educação e cultura em saúde à luz de Paulo Freire. Revista. Enfermagem UFPE on line, 11(12), 5122-5128. 10.5205/1981-8963-vlli12a25338p5128-2017.

Pereira, A. S., Shitsuka, D. M., Parreira, F. J., \& Shitsuka, R. (2018). Metodologia da pesquisa cientifica. UFSM. https://repositorio.ufsm.br/bitstr eam/handle/1/15824/Lic_Computacao_Metodologia-Pesquisa-Cientifica.pdf?sequence=1.

Progianti, J. M., \& Costa, R. F. (2008). A negociação do cuidado de enfermagem obstétrica através das práticas educativas na casa de parto. Escola Anna Nery [online], 12(4), 789-792. 10.1590/S1414-81452008000400025.

Seima, M. D., Michel, T., Méier, M. J., Wall, M. L., \& Lenardt, M. H. (2011). A produção científica da enfermagem e a utilização da teoria de Madeleine Leininger: revisão integrativa 1985-2011. Escola Anna Nery, 15(4), 851-857. 10.1590/S1414-81452011000400027.

Silva, J. L. L., Machado, E. A., Costa, F. S., Sousa, J. L., Taveira, R. P., Carolindo, F. M. ... Diniz, M. I. G. (2013). Reflexões sobre o cuidado transcultural e o processo saúde doença: contribuições para a assistência de enfermagem. Revista de Pesquisa Cuidado é Fundamental Online, 5(1). 3185-3195. 10.9789/2175$5361.2013 \mathrm{v} 5 \mathrm{n} 1 \mathrm{p} 3185$. 